\title{
Unterwanderung des Defizitverfahrens ist verboten, Effektivierung nicht
}

VB verfassungsblog.de/unterwandung-des-defizitverfahrens-ist-verboten-effektivierung-nicht/

Martin Nettesheim Di 13 Dez 2011

Di 13 Dez

2011

Es gehört zu den angeborenen Instinkten von Europapolitikern und Europarechtlern, auf ihrem Tätigkeitsfeld völkerrechtliche Abkommen als Fremdkörper und als Gefahr zu betrachten. Mit der rechtlichen Autonomie der EU und dem institutionellen Selbststand der Brüsseler Entscheidungsverfahren sind derartige Abkommen schwer zu vereinbaren: Sie drohen, das Kräfteverhältnis von Kommission, Parlament und Rat zu unterlaufen und die Wirkung der hier ergriffenen Maßnahmen zu beeinträchtigen. Aus der Brüsseler Binnenperspektive ist man denn auch geneigt, das EU-Regime als "geschlossenes Regime“ anzusehen, das ein zwischenstaatliches Handeln überhaupt nicht zulässt. Der Natur der EU als eines auf begrenzten Feldern tätigen, weiter von souveränen Staaten getragenen Verbands wird man damit aber nicht gerecht. Selbst dort, wo die Mitgliedstaaten Zuständigkeiten auf die EU übertragen haben, verlieren sie - von Ausnahmebereichen abgesehen - nicht ihre Handlungsbefugnisse. Die horizontale Koordination ist damit gerade im Bereich der Wirtschaftspolitik nicht schon von vorneherein ausgeschlossen.

Es ist damit nicht ausgeschlossen, dass sich die Mitgliedstaaten verbindlich festlegen, wie sie im Rat entscheiden werden, um dem Defizitverfahren nach Art. 126 AEUV verstärkte Effektivität zu verleihen. Eine derartige Absprache unterläuft nicht das Verfahren, sondern führt nur zu einer Selbstbindung des

Entscheidungsverhaltens. Den insofern souveränen Mitgliedstaaten steht es frei, die Entscheidungsfreiheit ihrer Repräsentanten im Rat auf diese Weise zu begrenzen. Eine völkervertragliche Vorabfestlegung des Entscheidungsverhaltens ist allerdings nur unter Beachtung der Loyalitätspflicht gegenüber der EU zulässig. Wenn und soweit es um eine Selbstbindung geht, mit der eine Effektivierung der Stabilitätspflicht erreicht werden soll, dient dies aber gerade den Zielen der EU und kann daher keine Verletzung der Unionstreue sein. Das in Art. 126 AEUV angelegte Defizitverfahren ist ein politischer Kompromiss, eine Art „lex imperfecta“. Entschließen sich 26 Mitgliedstaaten, dieses Verfahren durch Koordinierung ihres Entscheidungsverhaltens zu effektivieren, läuft dies weder dem Buchstaben noch dem Geist des EU-Rechts zuwider.

Ebenso wenig ist es unionsrechtlich ausgeschlossen, neben dem Defizitverfahren des Art. 126 AEUV ein Parallelverfahren einzurichten, mit dem sich 26 Mitgliedstaaten untereinander verschärften Sanktionen unterwerfen. Art. 126 AEUV lässt sich nicht dahingehend verstehen, dass die dort enthaltende Ineffizienz ein unantastbares Privileg der Mitgliedstaaten sein soll, über das sie nicht untereinander verfügen können. Man würde die Natur der wirtschaftspolitischen Koordinierung missverstehen, wenn man meinte, dort wären die Mitgliedstaaten bloß noch Exekutionsorgane des EU-Rechts. Art. 126 AEUV ist eine, aber eben nur eine Option, mit der die Mitgliedstaaten - alleine und je für sich, aber auch in koordinierter Form - dafür sorgen können, dass die Funktionsbedingungen einer Währungsunion gegeben sind. Selbstverständlich kann ein paralleles Sanktionsverfahren nur für Staaten greifen, die sich schärfer binden wollen. Bei der Einrichtung eines Parallelverfahrens zur Sanktionierung von Sündern sind allerdings rechtliche Grenzen insoweit zu beachten, als man sich der EU-Organe nur dann bedienen kann, wenn dies die Zustimmung aller 27 Mitgliedstaaten findet. Gegen ein Veto des UK wird eine Einschaltung der Kommission daher nicht möglich sein; eine implizite Zustimmung des UK würde allerdings ausreichen. Es bleibt daher festzustellen: Eine Unterwanderung des Defizitverfahrens ist den völkerrechtlich handelnden Mitgliedstaaten verboten, nicht aber eine Effektivierung sei es innerhalb des Art. 126 AEUV, sei es durch Einrichtung eines Parallelverfahrens.

\section{Martin Nettesheim ist Inhaber eines Lehrstuhls für Staats- und Verwaltungsrecht, Europarecht und Völkerrecht an der Universität Tübingen.}


effektivierung-nicht/. 